\title{
GEODINÂMICA DE SUPERFÍCIES DE APLANAMENTO, DESNUDAÇÃO CONTINENTAL E TECTÔNICA ATIVA COMO CONDICIONANTES DA MEGAGEOMORFOLOGIA DO BRASIL ORIENTAL
}

\author{
Roberto Célio Valadão \\ UFMG/IGEO - Rua Professor Manoel Casassanta, 288 - Apto 201 - Bairro Ouro Preto - Belo Horizonte - MG - \\ Cep 31310-390 - Tel.: (31) 9157-6962 /3498-1958 - e-mail: valadao@ufmg.br)
}

\begin{abstract}
Resumo
A megageomorfologia do Brasil Oriental é avaliada, neste trabalho, a partir da análise da desnudação continental mesocenozóica, das superfícies de aplanamento elaboradas em razão desse processo e dos soerguimentos crustais a ele associados. Muitos resultados alcançados diferem significativamente daqueles apresentados em trabalhos prévios, particularmente no que se refere à gênese e diversidade das superfícies de aplanamento, ao mecanismo de evolução da paisagem desde a fragmentação do Gondwana-Oeste, e à magnitude e amplitude dos soerguimentos crustais neocenozóicos.

A história fanerozóica do relevo do Brasil Oriental foi pontuada por episódios de intensa desnudação e pelo acúmulo de espessa sequência sedimentar em bacias marginais e interiores. Desde o Paleozóico, grande parte da área investigada permaneceu soerguida e em acelerado processo erosivo, particularmente a região em que atualmente se localiza a Serra do Espinhaço mineiro e baiano e a Chapada Diamantina. O processo de individualização da Placa Sul-Americana e abertura do Atlântico Sul, iniciado no Mesozóico, imprimiu novo ritmo à desnudação do continente, cuja justaposição ao caráter episódico dos soerguimentos crustais culminou, na área investigada, na elaboração de três amplas superfícies de aplanamento: (i) Superfície Sul-Americana; (ii) Superfície Sul-Americana I; (iii) Superfície Sul-Americana II. A elaboração dessas superfícies foi acompanhada pelo recuo do Grande Escarpamento, uma proeminente feição do relevo herdada do processo de rifteamento da margem continental leste brasileira. Esse escarpamento constitui um divisor hidrográfico de expressão regional, separando a bacia do Rio São Francisco, caracterizada pela reduzida capacidade desnudacional, daquelas bacias articuladas diretamente ao nível de base do Oceano Atlântico, mais agressivas.
\end{abstract}

Palavras-chave: superfícies de aplanamento; desnudação continental; soerguimento crustal; megageomorfologia.

\begin{abstract}
The megageomorphology of eastern Brazil is studied herein using as a major approach the analysis of the meso-cenozoic continental denudation and its relationships with planation surfaces and continental uplift. The results obtained differ significantly from those presented by previous authors, particularly in relation to those aspects as genesis and diversity of the planation surfaces, mechanisms of landscape evolution following the break-up of the western-Gondwana, and the magnitude and geographical limits of the neo-cenozoic crustal uplift.

The Phanerozoic history of the eastern Brazil relief was punctuated by episodes of intense denudation associated with accumulation of thick sedimentary sequences at the continental margin ad interior basins. Since the Paleozoic, the major part of the study area has experienced accelerated erosional processes, particularly the region occupied nowadays by the Serra do Espinhaço and the Chapada Diamantina. The break-up of the Gondwana and opening of the South Atlantic ocean, during the Mesozoic, has increased rates of continental denudation which has culminated in the elaboration of three planation surfaces: (i) Sul-Americana Surface; (ii) Sul-Americana I Surface; (iii) Sul-Americana II Surface. The sculpturing of these surfaces was
\end{abstract}


accompanied by the retreat of the Great Escarpment, an important feature of eastern Brazil relief inherited from the rifting processes that culminated in the formation of the present continental margin. This escarpment is nowadays an important continental divide, separating the São Francisco drainage basin, which is characterized by reduced denudation rates, from the drainage basins of rivers facing the Atlantic Ocean, which have much higher denudation rates.

Keywords: planation surfaces; continental denudation; crustal uplift; megageomorphology.

\section{Introdução}

Algumas porções continentais do globo, notadamente as áreas de escudos e maciços proterozóicos, estiveram submetidas a longo e intenso processo desnudacional responsável pela erosão de espessa sequência de rochas e pela exumação de complexos litoestruturais consolidados em níveis crustais profundos (LIMA \& VALADÃO, 2002). Nessas áreas a erosão excedeu quantitativamente a sedimentação e inibiu a geração de sequências estratigráficas espessas que, quando presentes, são comumente caracterizadas pela distribuição espaço-temporal fragmentada. Essa característica limita em muito o emprego de procedimentos sedimentológicos e estratigráficos na reconstrução paleogeográfica dos escudos. A Geomorfologia, em detrimento à escassez desses registros estratigráficos, tem se valido da abundância de paleoformas produzidas pela desnudação para propor reconstruções e modelos de evolução do relevo continental. Nesse contexto, o reconhecimento e caracterização das superfícies de aplanamento têm sido integrados a grande volume de dados produzidos pelas demais áreas das geociências na tentativa de se satisfazer a velha e primordial questão dos estudos geomorfológicos: a evolução do relevo continental.
Na porção oriental do território brasileiro, (i) a ampla distribuição geográfica das superfícies de aplanamento, (ii) seu excelente estado de conservação e o (iii) volumoso acervo de dados estratigráficos das bacias sedimentares interiores e marginais, oferecem condições favoráveis à análise integrada dessas informações com o objetivo de se compreender não só a estruturação dos macro-compartimentos geomorfológicos de trecho do Brasil Oriental - sua megageomorfologia -, como também sua evolução de longo-termo. Esse é o objetivo deste trabalho, o qual visa contribuir à elucidação de aspectos inerentes aos Grandes Domínios do Relevo da América Latina, instigante temática proposta ao autor pela Comissão Organizadora do Simpósio Nacional de Geomorfologia que, em sua sétima edição, agrega indiscutível relevância ao abrigar o II Encontro Latino-Americano de Geomorfologia. A área abordada neste trabalho está localizada na porção oriental brasileira onde ocupa larga faixa de orientação norte-sul, abrangendo extensas áreas dos estados da Bahia, Minas Gerais e Espírito Santo, além de pequenas porções dos estados do Piauí, Maranhão, Tocantins, Goiás e Rio de Janeiro (Fig. 01).

Figura 01 - Mapa de localização da área investigada. Legenda: I= cidades (VI: Vitória; BH: Belo Horizonte; SA: Salvador); 2 = hidrografia; $\mathbf{3}=$ limites interestaduais (Estados: RJ= Rio de Janeiro; ES= Espírito Santo; $M G=$ Minas Gerais; $B A=$ Bahia; $G O=$ Goiás; TO=Tocantins; $M A=$ Maranhão $; P I=$ Piauí $; S E=$ Sergipe $; A L=$ Alagoas $)$.

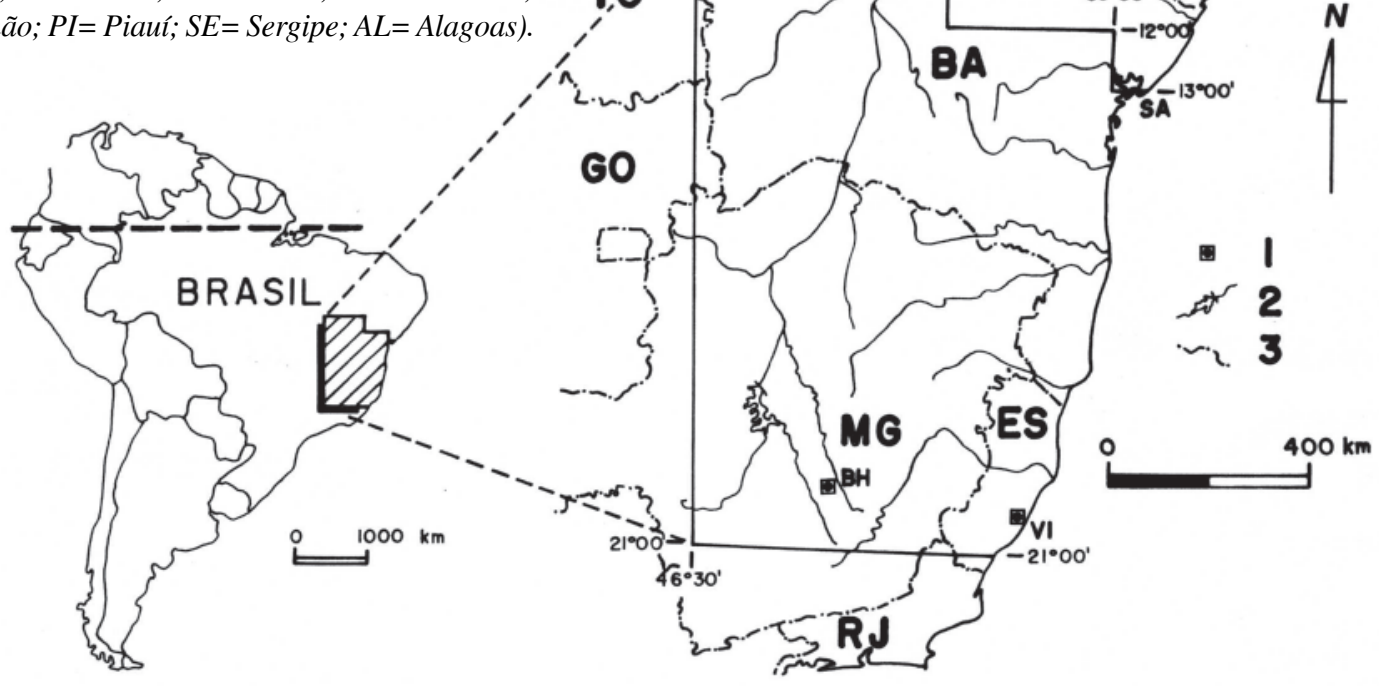




\section{Procedimentos metodológicos}

Os avanços mais recentes da geologia no trato da tecnoestratigrafia das bacias interiores e marginais do Brasil Oriental, aliados à disponibilidade de produtos de sensores remotos que traduzem com razoável fidelidade as principais feições do relevo continental, forneceram as condições ideais para que se efetivasse um programa intensivo de investigações de campo, com o objetivo de se estabelecer associações entre o processo de formação da margem continental, que bordeja a área investigada, e os eventos de desnudação que tiveram lugar sobre o continente. Nesse contexto, metodologicamente este trabalho foi apoiado na integração de procedimentos geológicos e geomorfológicos, com destaque para: (i) a interpretação de imagens de radar de visada lateral - RVL - que, em algumas áreas, foi associada a imagens de satélite LANDSAT, o que permitiu o reconhecimento e mapeamento dos remanescentes de superfície de aplanamento ainda presentes na área de estudo; (ii) o intensivo programa de investigações de campo, cuja finalidade principal foi caracterizar e descrever detalhadamente as formações superficiais que revestem os remanescentes das superfícies de aplanamento, notadamente a partir de suas exposições em cortes de estradas, rebordos escarpados de serras e chapadas, poços de inspeção e trincheiras; (iii) a elaboração de seções topográficas regionais a partir de base altimétrica disponível em mapas topográficos na escala de 1:250.000; (iv) a reconstrução morfo-altimétrica daqueles setores das superfícies de aplanamento atualmente já desmantelados pela desnudação, o que permitiu a elaboração de mapas paleotográficos; $(v)$ a avaliação das deformações tectônicas neocenozóicas segundo sua magnitude e espacialidade, através da superposição dos mapas de contorno altimétrico das superfícies de aplanamento, partindo-se do princípio de a diferença altimétrica entre superfícies de aplanamento distintas expressa a magnitude do soerguimento em uma dada localização e intervalo de tempo; (vi) a análise da organização atual da rede hidrográfica com o objetivo de se determinar qualitativamente sua funcionalidade e dinâmica; e, finalmente, (vii) a integração e compatibilização de dados de natureza diversa, tendo em vista a grande diversidade e complexidade dos parâmetros que acabaram por condicionar a megageomorfologia do trecho do Brasil Oriental aqui investigado.

\section{As superfícies de aplanamento no Brasil Oriental: elemento fundamental da paisagem geomorfológica macro-regional}

As superfícies de aplanamento no Brasil Oriental constituem traço fundamental da paisagem, embora em algumas áreas eventos desnudacionais neocenozóicos agressivos foram responsáveis, localmente, pelo desmantelamento de seus remanescentes. Todavia, o excelente estado de conservação delas em grande parte da área investigada permitiu o reconheci- mento e mapeamento de três superfícies distintas, denominadas, em ordem cronológica decrescente, de Superfície SulAmericana, Superfície Sul-Americana I e Superfície Sul-Americana II. Essas superfícies são facilmente reconhecidas no interior continental, onde a presença das rochas sedimentares subhorizontalizadas da Bacia Sanfranciscana favoreceu o recuo paralelo das encostas ( "backwearing"), formando escarpas que tão bem delimitam os aplanamentos. A ausência de rochas dessa natureza na fachada atlântica dificulta a diferenciação morfológica entre as superfícies Sul-Americana e SulAmericana I, embora as ocorrências de cada uma delas sejam comprovadas no campo a partir das distintas formações superficiais que as revestem. Um Grande Escarpamento separa o interior continental da fachada atlântica, além de configurar o divisor hidrográfico da bacia do Rio São Francisco com as bacias hidrográficas costeiras (rios Paraguaçu, de Contas, Pardo, Jequitinhonha e Doce). Esse escarpamento demarca significativa diferenciação altimétrica entre as superfícies mais elevadas localizadas no interior continental, daquelas mais rebaixadas que ocupam a fachada atlântica.

A superfície mais antiga reconhecida e mapeada na área investigada foi denominada Superfície Sul-Americana (Fig. 02 e 03), denominação essa proposta por $\operatorname{KING}(1956,1962)$ para designar a vasta planície produzida por desnudação entre o Cretáceo e o Terciário Médio. Embora ocorra grande discrepância entre a distribuição geográfica da Superfície SulAmericana mapeada por esse autor e aquela reconhecida e mapeada neste trabalho (VALADÃO, 1996, 1999b), sua denominação se justifica pelo fato de ambas terem sido elaboradas a partir da individualização da Placa Sul-Americana, notadamente após o encerramento da sedimentação mesozóica nas bacias do Paraná e Sanfranciscana. Essa superfície, apesar de reconhecida por vários pesquisadores, recebeu denominações diversas, a exemplo da Superfície de Campos de De MARTONNE (1943), do Peneplano Cretáceo de FREITAS (1951) e da Superfície Japi de ALMEIDA (1964). Ela alcançou comparativamente às demais superfícies reconhecidas e mapeadas neste trabalho o estágio mais avançado de aplanamento, ao transgredir e truncar arcabouço litoestrutural bastante diversificado. A sua reconstituição geométrica a partir de perfis projetados justapostos às seções topográficas regionais comprova que essa superfície assumiu, no interior continental, a arquitetura de amplo e suave sinformal de orientação aproximada norte-sul (Figura 04). Em direção a leste os flancos desse sinformal se articulam a um grande antiformal que, originalmente, se estendeu sobre a Serra do Espinhaço e a Chapada Diamantina. Os remanescentes da Superfície Sul-Americana são revestidos por manto de alteração profundo, geoquimicamente bastante evoluído e contendo teores elevados de ferro, embora seu substrato litológico seja bastante diversificado. É comum a presença de encrostamentos lateríticos, comumente recobertos por horizonte arenoso. 


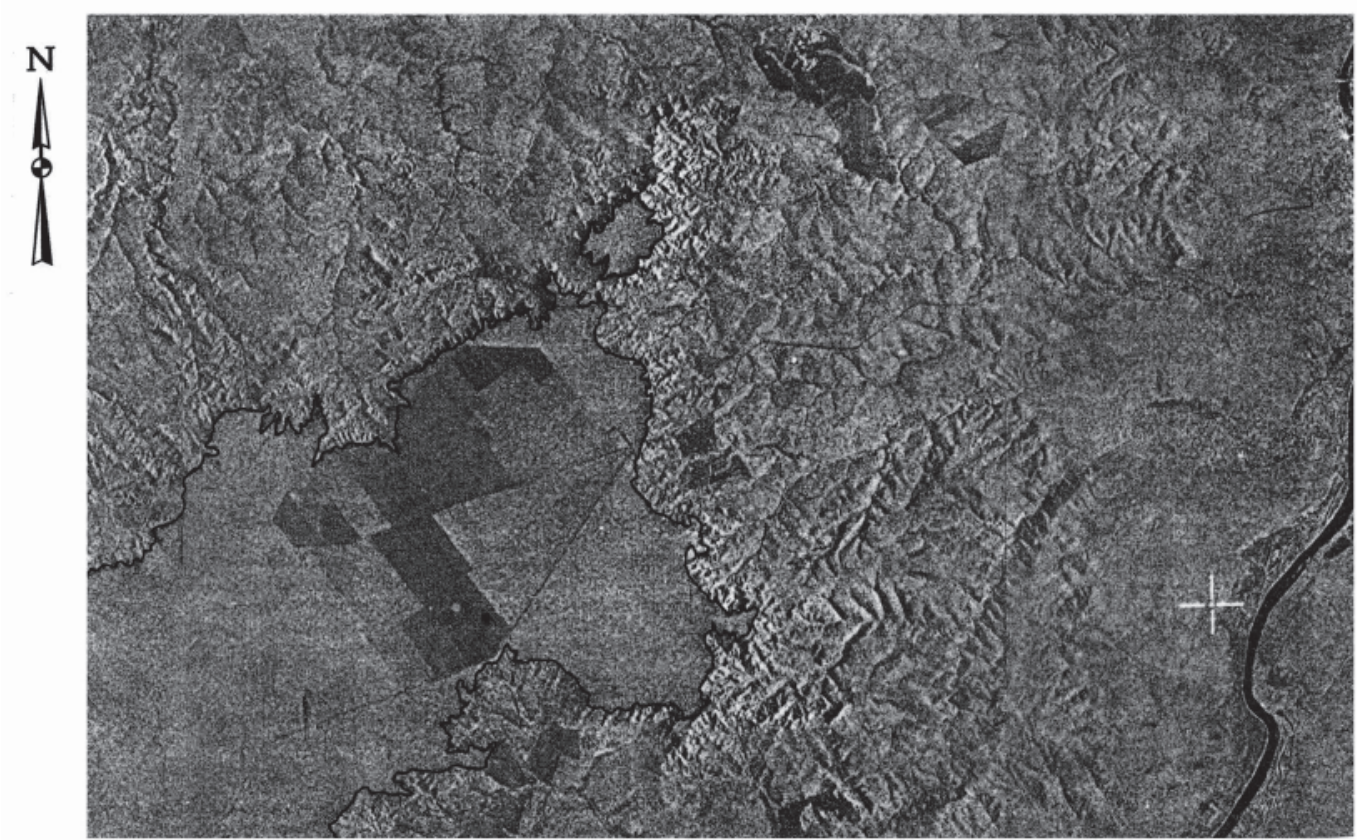

Figura 02 - Imagem de radar de remanescente da Superfície Sul-Americana localizado na 0 margem esquerda do Rio São Francisco/MG (Folha SE.23-V-B). O aplanamento de cimeira é cronocorrelato à Superfície Sul-Americana, sendo revestido por formações arenosas

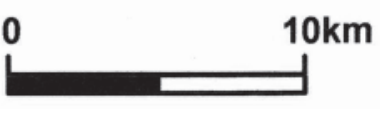
profundas e latolizadas desenvolvidas sobre a cobertura mesozóica da Formação Urucuia. Esse revestimento lhe atribui, nessa imagem, textura homogênea e contínua.

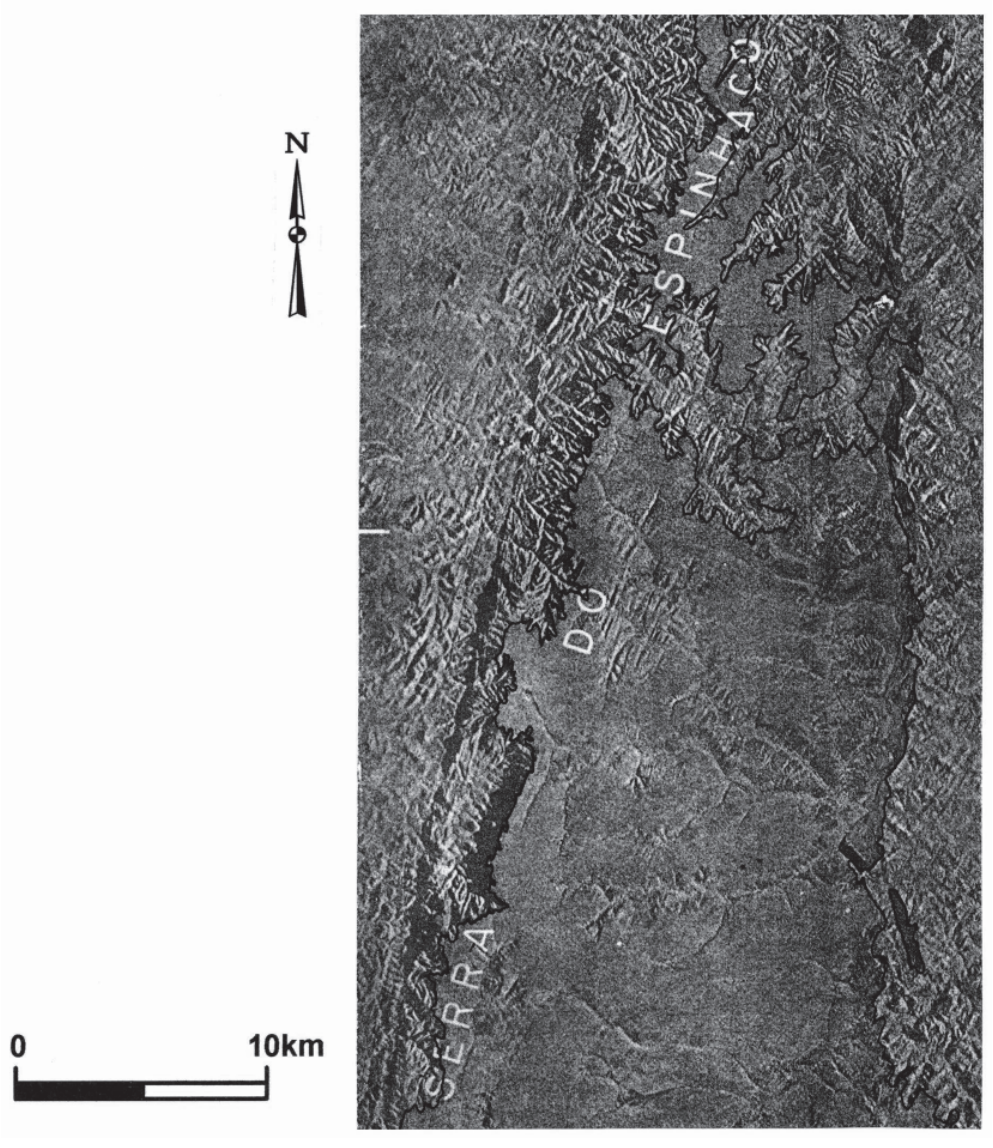

Figura 03 - Imagem de radar de remanescente da Superfície Sul-Americana localizado na porção mineira da Serra do Espinhaço (Folha SE.23-X$B)$. Essa superfície de aplanamento trunca indiferentemente as unidades litológicas do Supergrupo Espinhaço que, nessa área, são revestidas por formações superficiais arenosas. Observe que a continuidade desse revestimento e, consequentemente, da extensão da referida superfície, são localmente interrompidas pela incisão linear da rede hidrográfica. 


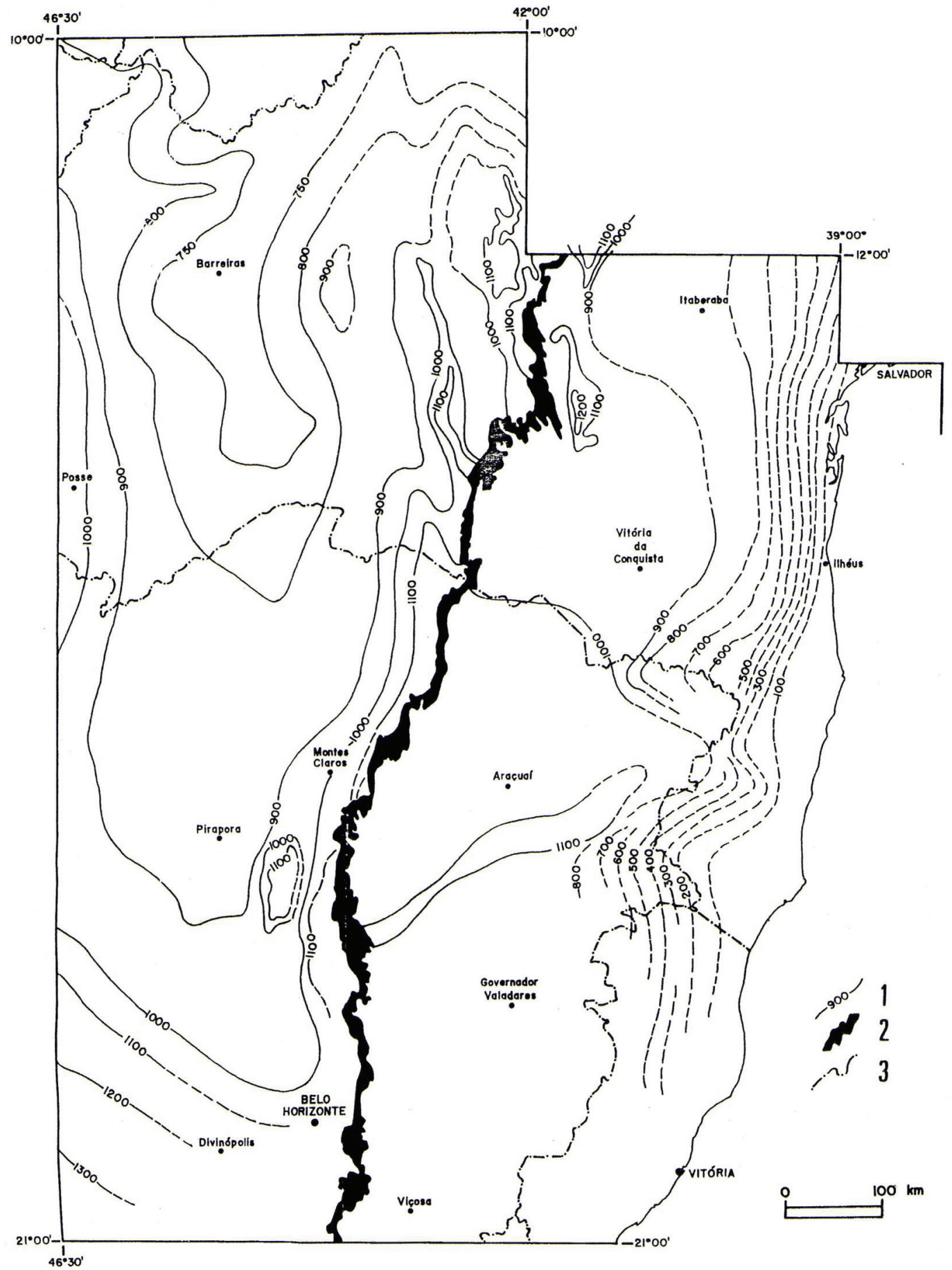

Figura 04 - Configuração e altimetria da Superfície Sul-Americana. Dados altimétricos, em metros, baseados no nível marinho atual. Legenda: 1= curvas de nível; $2=$ Grande Escarpamento (posição atual); $3=$ limite interestadual. Observe a arquitetura assumida, no interior continental, pela Superfície Sul-Americana, um sinformal de marcada orientação norte-sul.

É importante observar que, embora as conclusões de KING $(1956,1962)$ apontem para a existência de aplanamentos que antecederam a fragmentação do Supercontinente Gondwana, os seus remanescentes não foram encontrados durante as investigações de campo e o mapeamento das superfícies, salvo na forma de superfícies exumadas junto às coberturas mesozóicas da Bacia Sanfranciscana.

Partindo do princípio de que as demais superfícies reconhecidas na área investigada foram formadas a partir da disse- 
cação da Superfície Sul-Americana e que os seus remanescentes encontram-se geralmente nela embutidos, essas foram denominadas Superficie Sul-Americana I e Superficie Sul-Americana II. Essa denominação tem como objetivo estabelecer uma relação genética estreita delas com a Superficie Sul-Americana. Essa relação pode ser observada no manto de alteração que reveste a Superficie Sul-Americana, o qual desempenhou papel fundamental na geração das formações superficiais que revestem a Superfície Sul-Americana I, particularmente com relação à geração de depósitos supergênicos de manganês que, apesar de comumente encontrados associados a essa última, estiveram geneticamente associados à fase primária de concentração ocorrida durante a elaboração da Superfície Sul-Americana.

A Superfície Sul-Americana I (Fig. 05) não possui denominação específica na literatura geomorfológica, uma vez que a maioria dos autores sugere que sua gênese esteve associada exclusivamente à exumação de superfície fossilizada recoberta por rochas mesozóicas (KING, 1956, 1962; BRAUN, 1971). Todavia os resultados alcançados neste trabalho demonstram que essa superfície é revestida por formações superficiais que lhe atribuem uma identidade cronoestratigráfica própria, embora a sua elaboração tenha sido, em algumas áreas, favorecida pela presença de uma superfície mesozóica fossilizada. No interior continental essa superfície mergulha em direção à calha do Rio São Francisco, sugerindo que durante a sua elaboração esse rio apresentava traçado que, grosso modo, já se assemelhava ao atual. Localmente foi revestida por sedimentos fluviais que se relacionam à unidade basal do Grupo Barreiras, datada do Mioceno Superior/Plioceno.

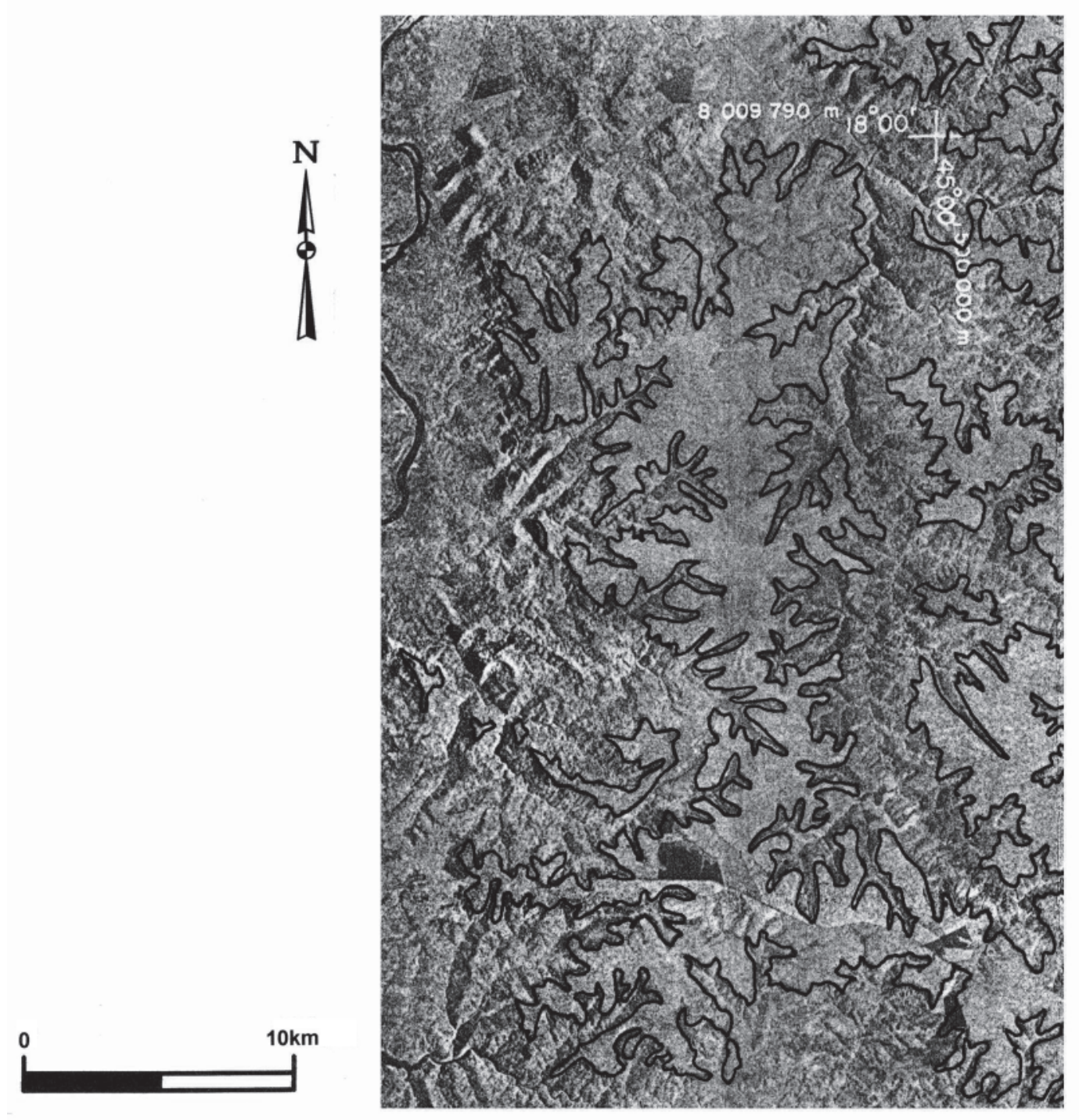

Figura 05 - Imagem de radar de remanescente da Superfície Sul-Americana I localizado na margem direita do Rio São Francisco, Serra do Repartimento/MG (Folha SE.23-Y-B). Essa superfície é caracterizada nessa imagem de radar pela sua textura heterogênea. 
A Superficie Sul-Americana II (Fig. 06 e 07) ocupa o piso das depressões interiores e sub-litorâneas, correspondendo, grosso modo, à Superfície Sertaneja proposta por AB'SABER (1969) para designar o aplanamento que ocupa as atuais depressões semi-áridas nordestinas. Todavia, verificou-se que sua extensão extrapola em muito o domínio morfoclimático do semi-árido sem, contudo, apresentar quaisquer descontinuidades de ordem geomorfológica com aqueles remanescentes localizados em domínios climáticos mais úmidos. No interior continental essa superfície é modelada em rampas que mergulham em direção às principais calhas fluviais (Fig. 08), ao passo que nas depressões sub-litorâneas as rampas mergulham em direção a linha de costa onde são conhecidas como tabuleiros costeiros. Embora parte dos remanescentes sub-litorâneos da $\mathrm{Su}$ perfície Sul-Americana II esteja modelado nas unidades do Grupo Barreiras, na medida em que essa superfície se distancia da linha de costa eles transgridem e truncam arcabouço litoestrutural diversificado, comprovando que sua ocorrência não está geologicamente restrita à arquitetura deposicional tabular dos sedimentos aluviais que compõem esse grupo.

Figura 06 - Imagem de radar de remanescentes das superfícies SulAmericana (SA), Sul-Americana I (SA I) $e$ Sul-Americana II ( $\boldsymbol{S A}$ II) localizados na margem esquerda do Rio São Francisco/ MG (Folha SE.23-V-D). Nessa imagem a superfície de cimeira é delimitada por escarpas ingremes e bem definidas (a), ao passo que as escarpas que estabelecem o contato entre as superfícies Sul-Americana I $e$ Sul-Americana II encontram-se desfiguradas e disseminadas no interior de áreas dissecadas (b).

\section{0}

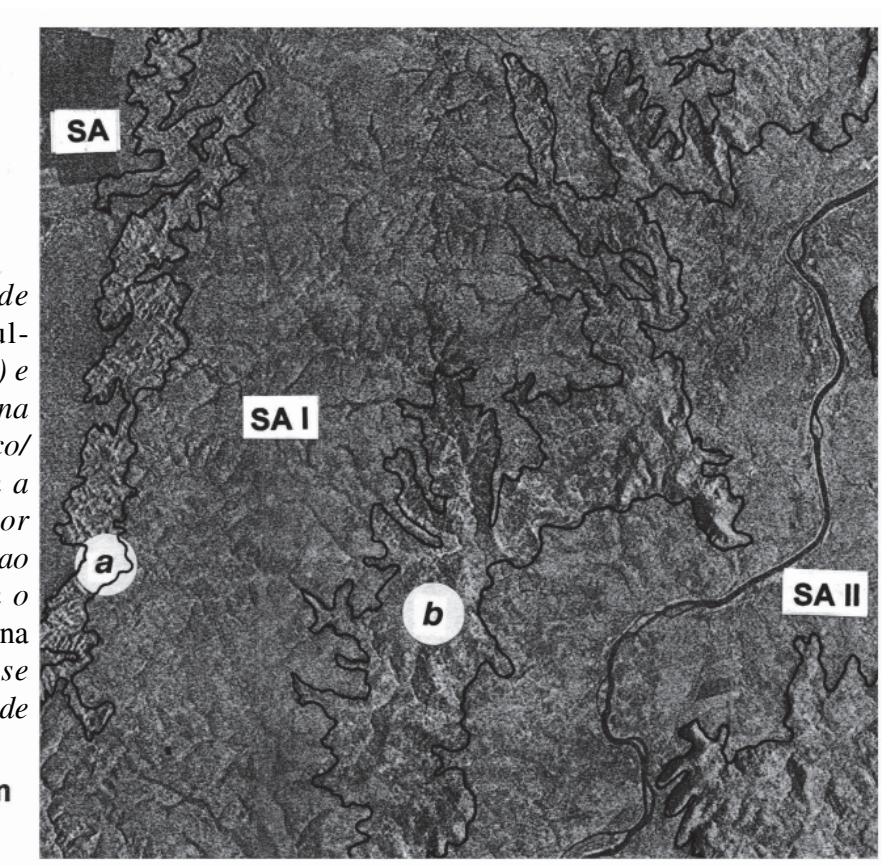

Figura 07 - Imagem de radar da Superfície SulAmericana II em posição sub-litorânea, na bacia do Rio Jequitinhonha/BA (Folha SE.24-V-B). O aplanamento, de textura heterogênea e áspera nessa imagem, é dissecado por rede hidrográfica densa.
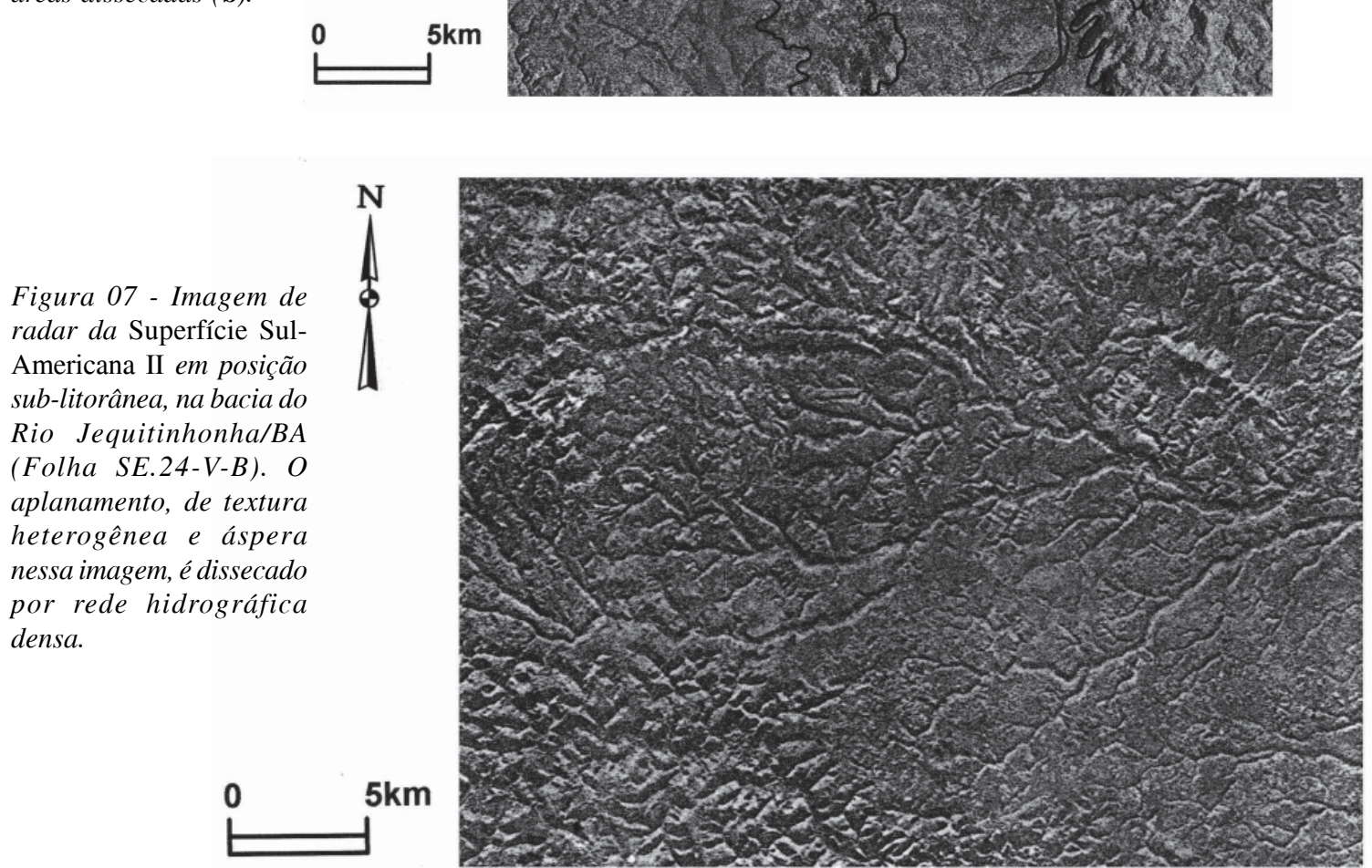


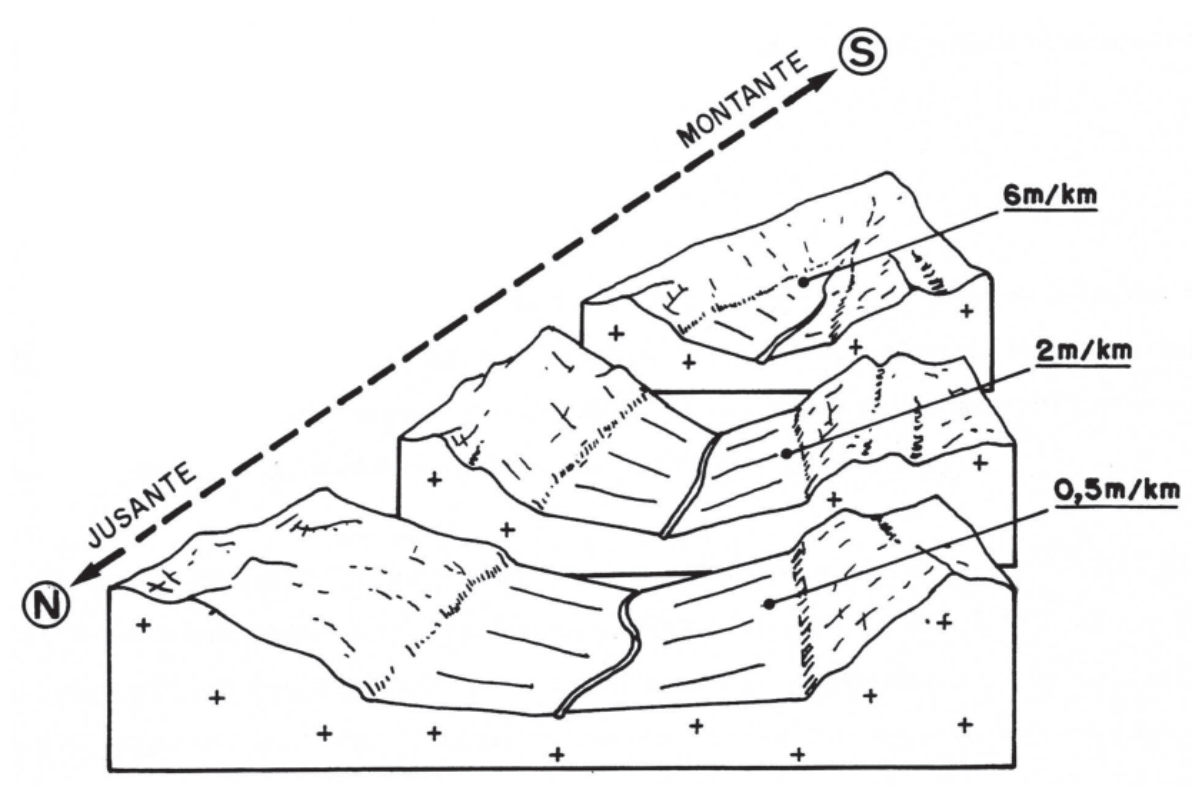

Figura 08 - Representação esquemática da Superfície Sul-Americana II na depressão do Rio Verde Grande (MG). Os valores apresentados correspondem à declividade média da superfície nos diferentes setores da depressão.

\section{A paisagem geomorfológica macro-regional na pers- pectiva temporal: uma cronologia da paisagem}

As etapas geodinâmicas de evolução da paisagem geomorfológica por que passou o Brasil Oriental, elaboradas a partir da análise da distribuição espacial e altimétrica das superfícies de aplanamento, como também de sua relação com o arcabouço litoestrutural das bacias sedimentares interiores e marginais, tem início com o Evento Brasiliano/Pan-Africano. Esse evento, iniciado no Proterozóico Superior e finalizado no Ordoviciano, foi responsável por ter imprimido, no fragmento litosférico em que se localiza o Brasil Oriental, matriz litoestrutural que passou a exercer papel fundamental sobre os eventos desencadeados ao longo do Fanerozóico. A história fanerozóica do relevo foi marcada por episódios de intensa desnudação da área continental e pelo acúmulo, seja em bacias interiores ou marginais, de espessa pilha sedimentar. Nesse contexto, grande parte da área reportada neste trabalho permaneceu soerguida e em acelerado processo desnudacional desde o Paleozóico, particularmente a região atualmente ocupada pela Serra do Espinhaço mineiro e baiano e pela Chapada Diamantina (VALADÃO, 1999a; VALADÃO \& DOMINGUES, 1994).

O estágio sin-rifte da atual margem continental que bordeja a área investigada foi precedido ao sul por uma elevação dômica da crosta, motivada por intensa atividade magmática. Ao norte esse rifteamento assumiu característica inter-dômica (Fig. 09). Durante o estágio sin-rifte propriamente dito ocorreu o quebramento da crosta e, consequentemente, a formação de proeminentes escarpas de falhas associadas aos flancos de rifte em soerguimento, criando um Grande Escarpamento que impôs ao Brasil Oriental a estruturação de uma rede hidrográfica dual. Esse escarpamento passou a configurar um divisor hidrográfico de expressão regional, individualizando bacias de drenagem agressivas voltadas para o interior dos riftes, daquelas outras, de menor capacidade desnudacional, voltadas para o interior continental (Fig. 10). Nesse contexto, teve início a elaboração da Superfície Sul-Americana, no Aptiano, quando a rede hidrográfica voltada para o interior dos riftes se articulou ao nível de base do precoce Atlântico Sul. Embora tenham ocorrido significativos episódios de erosão e soterramento da área investigada após o Aptiano, todos eles contribuíram para a marcante regularidade topográfica alcançada por essa superfície, cujo processo de elaboração se estendeu até o Mioceno Médio (Fig. 11), quando parcela considerável da área investigada foi soerguida, o que resultou na aceleração da desnudação continental e, consequentemente, no rejuvenescimento de seu relevo. 


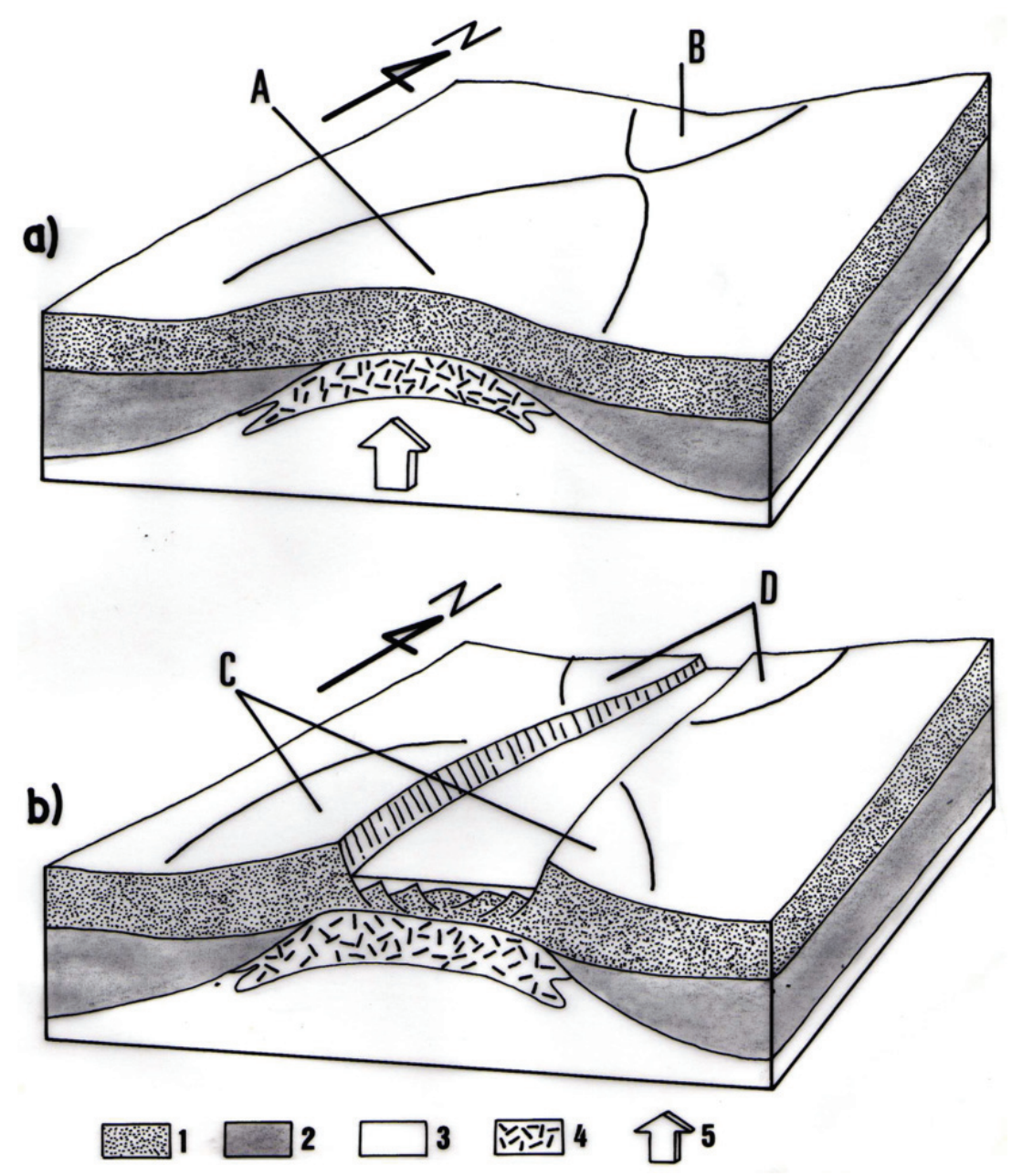

Figura 09 - Configuração geomorfológica esquemática durante as fases pré-rifte $(\boldsymbol{a})$ e sin-rifte (b) da margem continental leste brasileira. Legenda: $\boldsymbol{A}=$ arqueamento dômico; $\boldsymbol{B}=$ depressão interdômica; $\boldsymbol{C}=$ rifteamento dômico (vulcânico); $\boldsymbol{D}=$ rifteamento interdômico (nãovulcânico); $\mathbf{1}=$ crosta; $\mathbf{2}=$ manto litosférico; $\mathbf{3}=$ astenosfera; $\mathbf{4}=$ underplating magmático; $\mathbf{5}=$ soerguimento.

A tectônica miocênica, embora tenha adquirido distribuição geográfica generalizada, concentrou-se ao longo de quatro grandes eixos de soerguimento, assim denominados: Alto Paranaíba; Arinos - Alvorada do Norte; Espinhaço - Chapada Diamantina; Geraizinhos Maracá (Fig. 12). A maior magnitude de soerguimento ocorreu no interior continental, notadamente nas bordas dos Cráton do São Francisco (300m - 550m) (VALADÃO \& DOMINGUES, 1999). Em razão da reduzida magnitude do soerguimento miocênico na fachada atlântica (o qual não excedeu os 150m), foi produzida, em algumas áreas, a convergência das superfícies Sul-Americana e Sul-Americana I. Esse soerguimento, tendo em vista seu alcance espacial, acabou por resultar na incisão da rede hidrográfica regional, criando as condições favoráveis ao despimento desnudacional dos remanescentes aplanados da Superfície Sul-Americana, sobretudo ao longo das principais calhas fluviais. Esse despimento deu início à elaboração da Superfície Sul-Americana I, cujos remanescentes ocorrem embutidos naqueles aplanamentos de cimeira cronocorrelatos à Superfície Sul-Americana. 


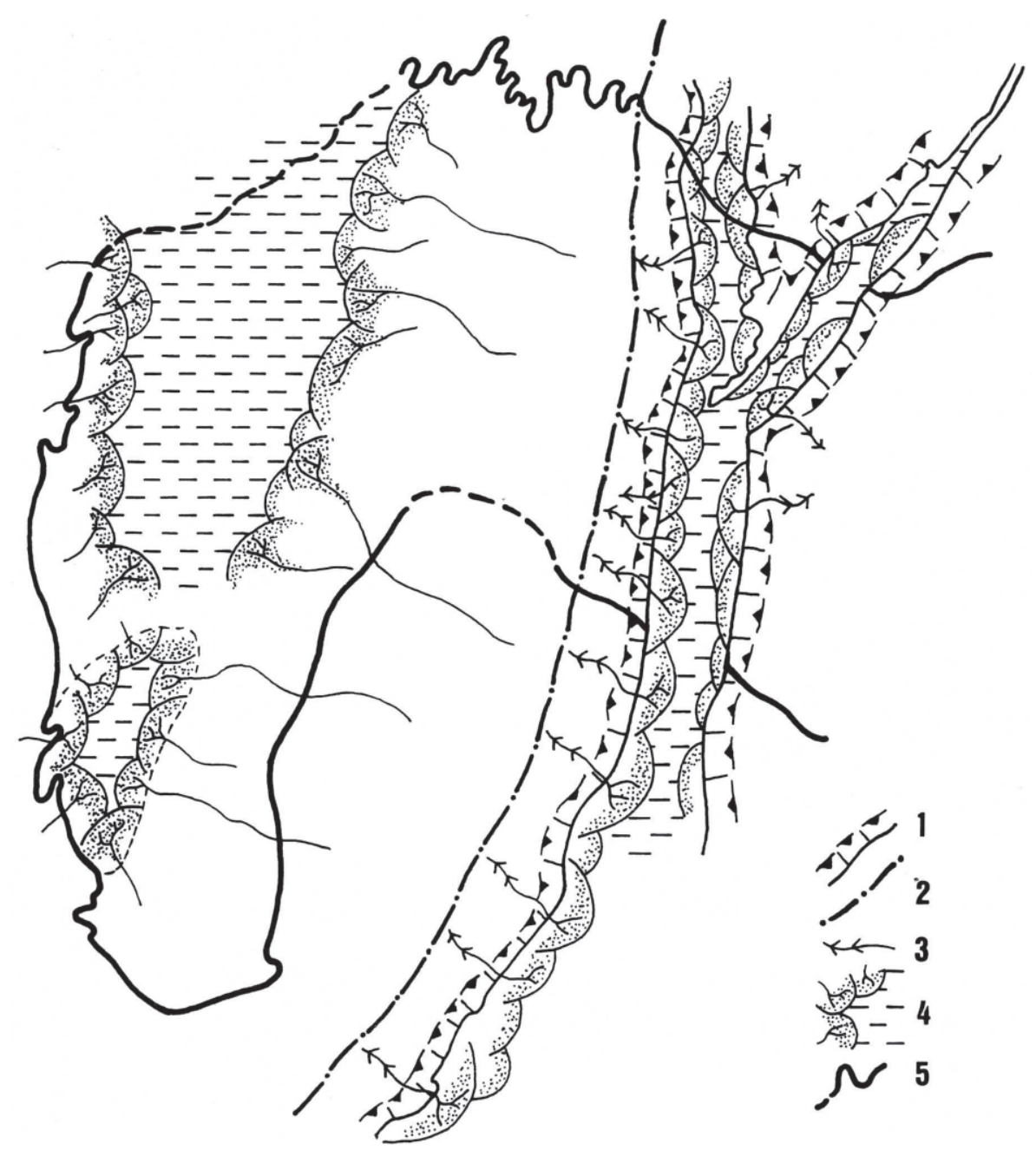

Figura 10 - Paleogeografia de trecho do Brasil Oriental no Neocomiano (fase sin-rifte). Legenda: 1 - Grande Escarpamento; $2=$ divisor hidrográfico; $\mathbf{3}$ = retração erosiva das cabeceiras de drenagem; $\mathbf{4}=$ sedimentos flúvio-lacustres; $\mathbf{5}=$ limites do Cráton do São Francisco.

Mais tarde, ao longo do Plioceno Superior, a área investigada foi alvo de novo episódio de soerguimento, porém, a esse tempo, concentrado na fachada atlântica (até 600m) (Fig. 13), embora movimentações de menor amplitude tenham ocorrido de modo generalizado, interrompendo o processo de elaboração da Superfície Sul-Americana I e iniciando a abertura das atuais depressões interplanálticas e sublitorâneas. Gargantas epigênicas que hoje abrigam alguns trechos de canais fluviais foram escavadas em consequência desse soerguimento.

\section{Convergência espaço-temporal de processos e for- mas na compreensão da megageomorfologia do Bra- sil Oriental}

A gênese de cada uma das superfícies de aplanamento aqui retratadas foi dependente da convergência espaço-temporal de uma série de condições geodinâmicas, dentre as quais se destaca a estabilidade do nível de base à desnudação continental. Acredita-se que essa estabilidade foi alcançada em condições de quietação tectônica, ao passo que os soerguimentos crustais episódicos rejuvenesceram a paisagem continental na medida em que propiciaram o aumento da amplitude vertical do relevo. 
Geodinâmica de superfícies de aplanamento, desnudação continental e tectônica ativa como condicionantes da megageomorfologia do Brasil oriental

Figura 11 - Paleogeografia da área investigada no eoTerciário. Observe que a Superfície Sul-Americana se distribui em dois níveis altimétricos distintos, separados por um proeminente escarpamento Legenda: $\boldsymbol{A}=$ Grande Escarpamento; $\boldsymbol{B}=$ Bacia Sanfranciscana; $\mathbf{1}=$ sedimentos mesozóicos; $2=$ crosta continental; $\mathbf{3}=$ crosta oceânica; $\mathbf{4}=$ manto litosférico; 5 = astenosfera.
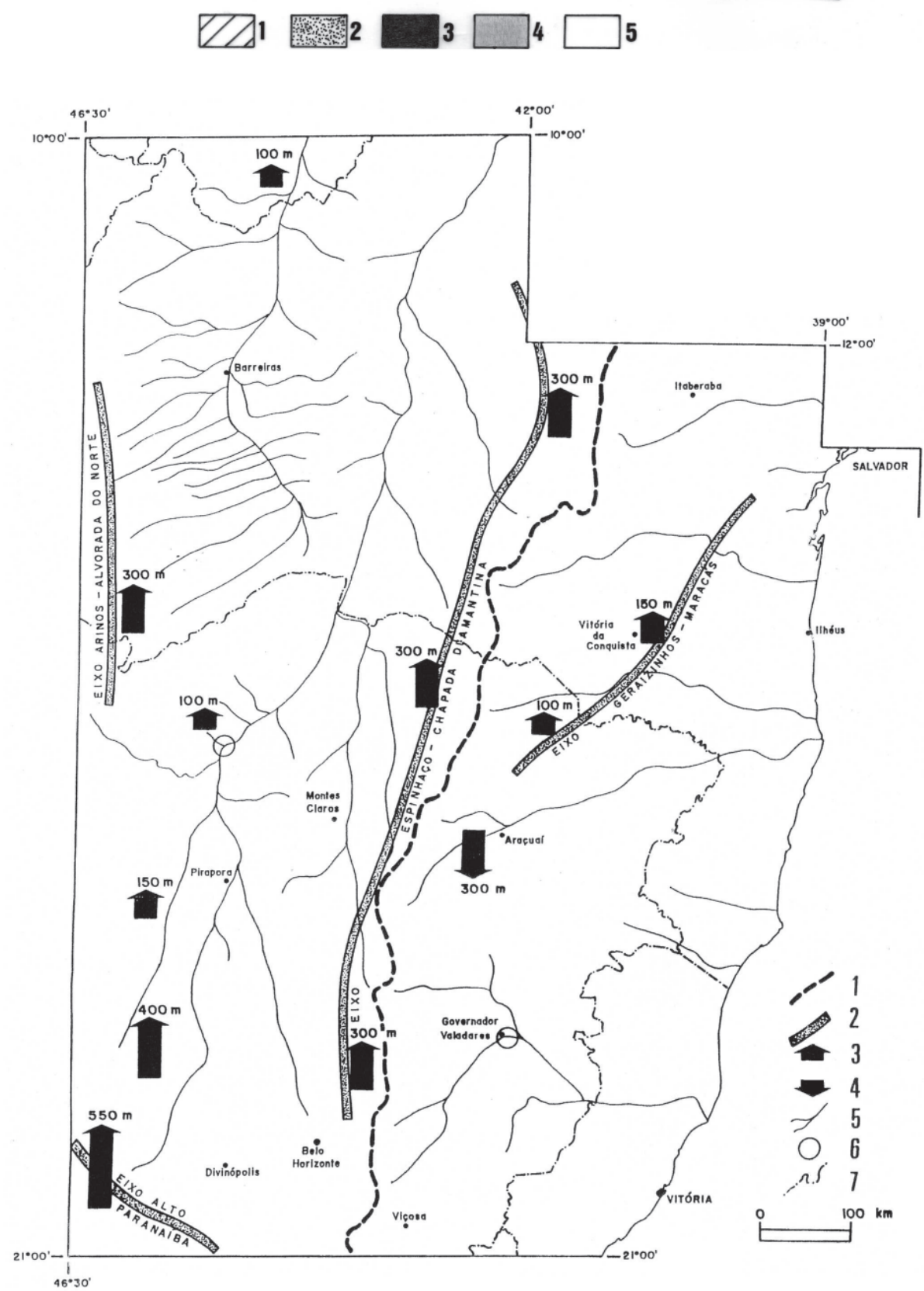

Figura 12 - Reconstrução dos principais elementos da rede hidrográfica no Mioceno, apresentando os principais eixos de soerguimento. Legenda: $\mathbf{1}=$ Grande Escarpamento; $2=$ eixo de soerguimento; $3=$ soerguimento (em metros); $4=$ subsidência (em metros); $5=$ rede hidrográfica; $\mathbf{6}=$ captura fluvial; $7=$ limite interestadual. 


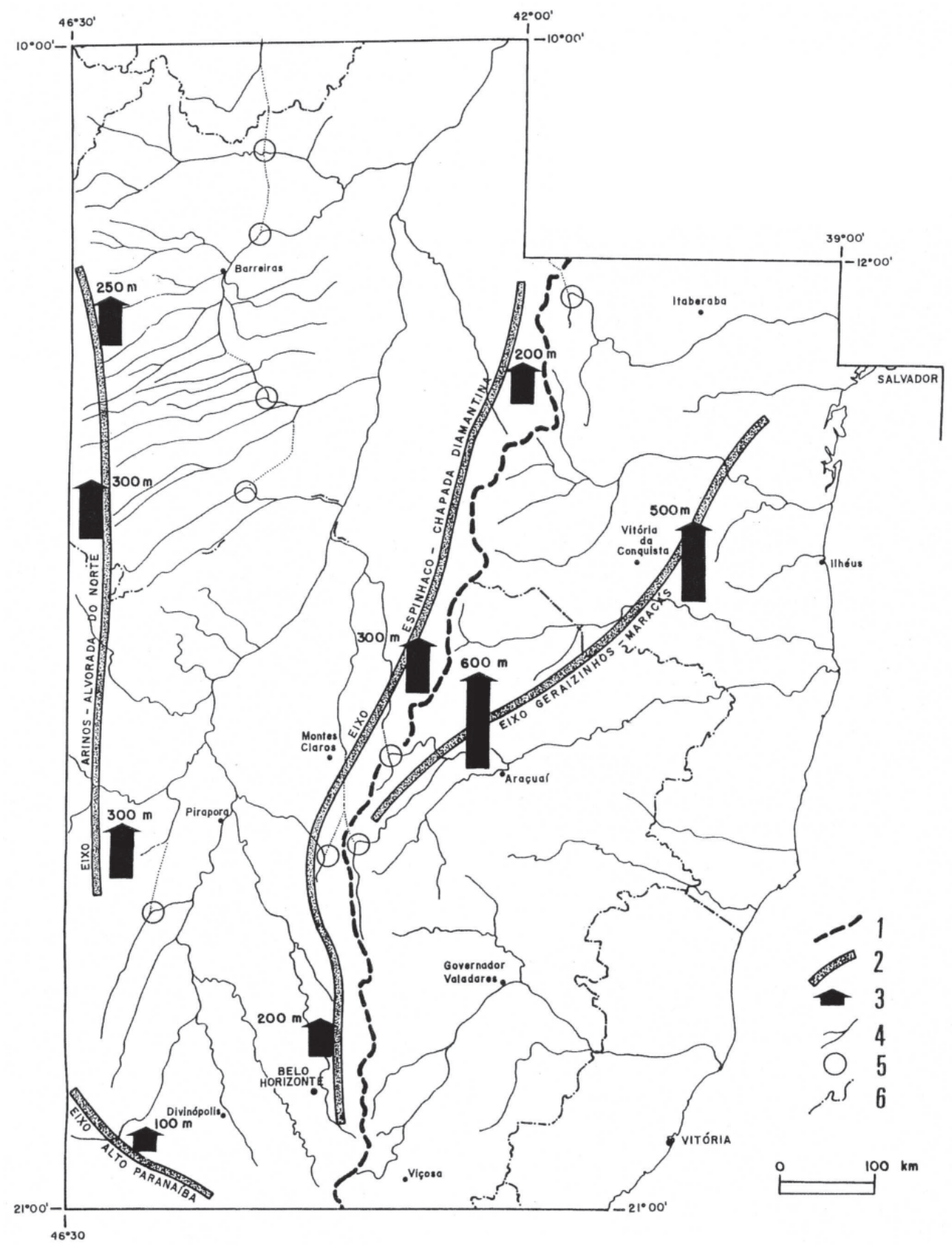

Figura 13 - Reconstrução dos principais elementos da rede hidrográfica no Plio-Pleistoceno, apresentando os principais eixos de soerguimento. Legenda: $\mathbf{1}=$ Grande Escarpamento; $\mathbf{2}=$ eixo de soerguimento; $\mathbf{3}=$ soerguimento $($ em metros); $\mathbf{4}=$ rede hidrográfica; $\mathbf{5}=$ captura fluvial; $\mathbf{6}=$ limite interestadual. 


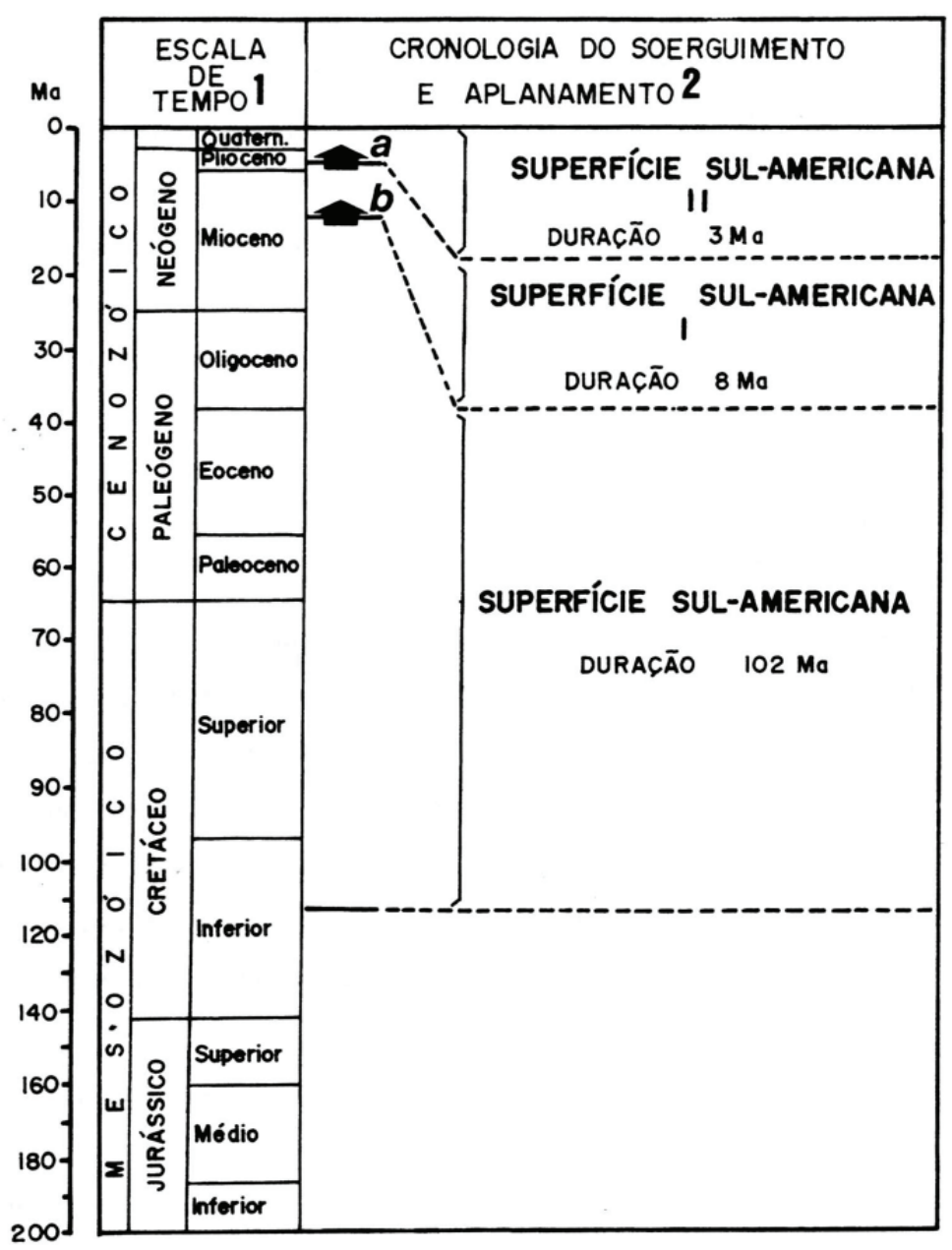

Figura 14: Cronologia de soerguimento e elaboração das superfícies de aplanamento do Brasil Oriental. Legenda: $1=$ Observe que a partir de 100Ma ocorre mudança na representação da escala; 2 = As setas verticais enfatizam os episódios de soerguimento (a: soerguimento miocênico; b: soerguimento pliocênico).

A mais alta frequência dos eventos de elaboração das superfícies de aplanamento no neocenozóico parece estar diretamente associada à intensificação das reativações tectônicas a partir do Mioceno. Essa intensificação não é exclusiva da área investigada, mas, ao que tudo indica, um comportamento de escala global. Os longos intervalos de quietação tectônica que prevaleceram durante o Gondwana vêm sendo progressivamente substituídos, desde o Mesozóico, por espasmos tectônicos cada vez mais frequentes, cuja atuação tem afetado não só as bordas das placas em franca atividade tectônica (BENJAMIM et al., 1987), como também o seu interior (BEHRENDT \& COOPER, 1991).

Quanto à curta duração do evento de elaboração das superfícies Sul-Americana I e Sul-Americana II, é importan- te observar que essas superfícies estão, em grande parte, embutidas na Superfície Sul-Americana e com ela estabelecem íntima filiação genética. A longa duração do evento de elaboração da Superfície Sul-Americana possibilitou o truncamento de arcabouço litoestrutural variado, composto por rochas de resistência bastante diferenciada. Nesse contexto, a elaboração da Superfície Sul-Americana I foi favorecida pela presença prévia de uma topografia regularizada, de baixa amplitude vertical, sustentada por manto de alteração espesso. Em muitos locais a sua elaboração esteve subordinada simplesmente ao despimento parcial desse manto, cuja desnudação foi auxiliada, em algumas áreas do interior continental, pela presença da discordância erosiva que marca o contato do embasamento da Bacia Sanfranciscana 
com a sua cobertura mesozóica. Por outro lado, a elaboração da Superfície Sul-Americana II foi favorecida, no interior continental, pela presença quase que generalizada dos metapelitos do Supergrupo São Francisco, cuja resistência à erosão é pequena, e, na fachada atlântica, pela disposição tabular dos arenitos e conglomerados do Grupo Barreiras, embora essa superfície não esteja espacialmente restrita às ocorrências desses sedimentos.

A duração extremamente longa para o desenvolvimento da Superfície Sul-Americana não deve significar que a sua elaboração tenha envolvido um processo único, contínuo e ininterrupto. Apesar desse fato, não foi observado, por meio dos procedimentos de gabinete e campo empregados, nenhum indício geomorfológico que permita individualizar superfícies distintas naquelas áreas ocupadas pela Superfície SulAmericana. Todavia, caso essas superfícies tenham existido, a Superfície Sul-Americana deve ser entendida como resultante da convergência espaço-temporal de mais de um evento de aplanamento.

\section{Referências Bibliográficas}

AB'SABER, A. (1969). Participação das superfícies aplainadas nas paisagens do nordeste brasileiro. Geomorfologia, (19)1-38.

ALMEIDA, F.F.M. de (1964). Fundamentos geológicos do relevo paulista. Instituto Geográfico e Geológico, Boletim 41:169-263.

BEHRENDT, J.C. \& COOPER, A. (1991). Evidence of rapid Cenozoic uplift of the shouder escarpment of the Cenozoic West Antartic rift system and speculation on possible climate forcing. Geology, 19:315-319.

BENJAMIM, M.T.; JOHNSON, N.M. \& NAESER, C.W. (1987). Recent rapid uplift in the Bolivian Andes: evidence from fission track dating. Geology, $15: 680-683$

BRAUN, O.P.G. (1971). Contribuição à geomorfologia do Brasil central. Rev. Bras. Geografia, 32(3):39.
De MARTONNE, E. (1943) Problemas morfoclimáticos do Brasil tropical atlântico. Rev. Bras. Geografia, 5(4):523-550.

FREITAS, R.O. (1951). Relêvos policíclicos na tectônica do Escudo Brasileiro. Bol. Paulista Geografia, 7:3-19.

KING, L.C. (1956). Geomorfologia do Brasil Oriental. Rev. Bras. Geografia, 18(2):147-265.

KING, L.C. (1962). Morphology of the Earth. London, Oliver and Boyd, 699p.

LIMA, O.N.B. \& VALADÃO, R.C (2002). Evolução do relevo adjacente à margem continental oriental brasileira: indicadores geológicos. In: Congresso Brasileiro de Geologia, XLI, João Pessoa, 2002. Anais..., João Pessoa, SBG, vol 1.

VALADÃO, R.C. \& DOMINGUES, J.M.L. (1994). Opening of the South Atlantic Ocean and denudation of the São Francisco Craton, Brazil. In: International Sedimentological Congress, 14, Recife, 1994. Abstracts..., Recife, IAG, S10-S11.

VALADÃO, R.C. \& DOMINGUES, J.M.L. (1999). Deformação tectônica neocenozóica no Brasil Oriental: zonalidade e magnitude. In: Congresso da Associação Brasileira de Estudos do Quaternário, 7, Porto Seguro, 1999. Anais..., Porto Seguro, ABEQUA.

VALADÃO, R.C. (1996). King e a Geomorfologia do Brasil Oriental: uma reavaliação. In: Congresso Brasileiro de Geologia, XXXIX, Salvador, 1996. Anais..., Salvador, SBG, vol.2, p:511-513.

VALADÃO, R.C. (1999a). Evolução do Cráton do São Francisco e da fachada atlântica brasileira no Fanerozóico. In: VII Simpósio de Geologia do Centro-Oeste e X Simpósio de Geologia de Minas Gerais, Brasília, 1999. Anais..., Brasília, SBG, p:108-109.

VALADÃO, R.C. (1999b). Superfícies de aplanamento do Brasil Oriental: mapeamento, caracterização e geodinâmica. In: VII Simpósio de Geologia do Centro-Oeste e X Simpósio de Geologia de Minas Gerais, Brasília, 1999. Anais..., Brasília, SBG, p:107-108. 